\title{
FUNKEIROS, TIMBALEIROS E PAGODEIROS: NOTAS SOBRE JUVENTUDE E MÚSICA NEGRA NA CIDADE DE SALVADOR*
}

\begin{abstract}
RESUMO: Neste artigo, pretendo discutir como, num contexto racializado da associação entre juventude negra e música, surgem experiências que se desenvolvem como marcas identitárias, crítica social e ratificação de hierarquias raciais, de classe e gênero. Para tanto, trabalho com as idéias de juventude e geração como dado biológico, tanto quanto social e histórico, e com a idéia de música como sentido compartilhado. Além disso, rediscuto minhas notas etnográficas e de outros autores que refletiram sobre a relação entre música e juventude negra, cujos jovens observados, em contextos diversificados, são basicamente suburbanos, pobres e "negro-mestiços" com baixo grau de escolaridade, alguns com baixa capacidade de consumo, outros consumidores ansiosos. Concluo apontando para a importância da música como instrumento configurador de uma experiência juvenil e negra afro-diaspórica, mas também como instrumento repositor de antigas dessemelhanças que não estão nos genes.
\end{abstract}

ARI LIMA*

Palavras-chave: Juventude. Cultura negra. Bahia. África.

* Como autor, assumo a responsabilidade por todos os pontos de vista e idéias apresentados neste artigo. Estou certo, entretanto, que o amadurecimento dos mesmos são resultado da interlocução com informantes e com colegas que discutem temáticas próximas a que apresento. Neste sentido, agradeço a todos aqueles que, anonimamente, contribuíram para a realização deste artigo e especialmente a Osmundo Pinho, pelas críticas e comentários.

* Professor substituto do Departamento de Antropologia da Universidade Federal da Bahia (Uғва) e doutorando em Antropologia Social na Universidade de Brasília (UnB). E-mail: ari66@ig.com.br 
FunKeIROS, TIMBALEIROS E PAGOdeIROS:

Notice about youth and the black music of Salvador City

ABSTRACT: In this article, I intend to discuss how, in the racialized context of the association between black youth and music, experiences arise and develop as identity marks, social criticism and the ratification of racial, class and gender hierarchies. To do so, I work with the idea of youth and generation as not only a biological, but also a social and historical data, and with the idea of music as a shared sense. Besides, I discuss my own ethnographical observations as well as those of other authors who reflected on the relationship between music and black youth and have basically observed, in various contexts, young, poor, partly Negro suburbanites with low schooling, some having a low buying power, others being anxious consumers. I conclude pinpointing the importance of music as a configuration instrument for a youthful and black Diaspora experience, but also as an instrument that renews old dissimilarities that are not genetic.

Key words: Youth. Black Culture. Bahia. Africa.

$F$

reqüentemente, o debate sobre juventude em contextos urbanos enfoca questões como evasão escolar, violência e criminalidade, abandono social, sexualidade, inserção no mercado de trabalho ou conflito de geraçôes. Temas que esboçam uma preocupação em torno de desastres sociais e perspectivas de futuro para cidadãos em formação. $\mathrm{Na}$ cidade de Salvador, capital do estado da Bahia, estas questôes aparecem num contexto onde, segundo estatísticas oficiais, cerca de $80 \%$ da população é formada por negros (pretos e pardos). Estes negros são as vítimas mais constantes da repressão policial, são quase invisíveis nos meios de comunicação, são as maiores vítimas do desemprego, exercem as funções que exigem menor qualificação, recebem salários mais baixos e mais dificilmente ascendem no emprego; têm maior dificuldade de acesso ao ensino superior e público e tendem a ocupar vagas nos cursos superiores menos prestigiados (Castro \& Barreto, 1998; Queiroz, 2000). Neste contexto, os baianos, de um modo geral, e os jovens negros, em particular, cultivam um sentimento positivo de diferença em relação ao Brasil e ao mundo (Pinho, 1998a), assim como um sentimento de indiferenciação racial; evadidos da escola, propensos à violência, ao crime e ao desemprego, estes jovens negros são objeto de imagens e representaçôes culturais que orientam a idéia de uma juventude alegre, lasciva, musical, festiva e exótica. A perspectiva ci- 
dadã desta juventude em Salvador me parece, portanto, fundamentalmente racializada. ${ }^{1}$

Neste artigo, baseado em notas de vários autores (Vianna, 1988; Cecchetto, 1997; Silva, 1997; Sansone, 1997; Pinho, 1998b; Godi, 2001) e nas minhas próprias investidas etnográficas (Lima, 1997; 2000), pretendo discutir a música, ${ }^{2}$ em seu aspecto racialista, como configuradora de sentido para uma idéia de juventude negra em Salvador. Acredito que, se por um lado, através da música, nos últimos 30 anos, geraçôes sucessivas de jovens negros, conscientes dos seus limites para aquisição de cidadania, elaboraram formas musicais que se transformaram em expressão de identidade juvenil, em estratégias de afirmação étnica e racial, em projetos anti-racistas, por outro lado, estas mesmas formas musicais serviram para reatualizar estereótipos em relação ao negro e controlar as perspectivas de uma juventude negra expressiva e majoritária.

\section{Juventude e geração}

A princípio, a noção de juventude se define por um aprofundamento biológico do processo vital de um indivíduo. Neste processo, os jovens passam por notórias alterações orgânicas e anatômicas que o distinguem de uma criança ou de um indivíduo adulto. Mas, justamente, enquanto decorre este processo orgânico e anatômico, os jovens costumam também sofrer uma forte pressão social. Isto porque se manifesta na família, na escola, no segmento social de origem ou entre os grupos de amigos uma expectativa em torno de uma consciência juvenil apta à aceitação de novos papéis sociais, à aquisição de responsabilidades e elaboração de projetos de futuro. A juventude se torna, então, mais do que o aprofundamento biológico do processo vital do indivíduo, um aprofundamento crítico, ritualizado, integrador ou libertário em relação ao tempo, ao espaço e à ordem social. Historicamente determinado, este processo vital reflete injunçôes de classe, raça, gênero, escolaridade e mesmo dos modelos de relaçôes entre uma "geração" antecedente e outra posterior.

Uma das formas de conferir unidade e maior clareza de sentido à noção de juventude é associá-la à idéia de geração. Marialice M. Foracchi (1972) afirma que se define uma geração através de um estilo de ação peculiar, uma uniformidade de locação social estranhos a uma geração anterior. Isto significa que uma geração compartilha experiências, situações de vida e oportunidades de trabalho, benefí- 
cios e opressões, tensões e alegrias prefiguradas por um modo geracional de locação na estrutura social.

A análise do fenômeno da locação social permite estabelecer diferenças entre o fenômeno das geraçóes e dos grupos sociais, dando a unidade das gerações como sendo essencialmente constituída pela similaridade de locação. Só é possível, contudo, caracterizar o fenômeno da similaridade de locação, quando se especifica a natureza da estrutura através da qual os grupos de locação emergem na realidade histórico-social. A geração constitui, assim, uma modalidade particular de localização social. Há uma "tendência", inerente a cada geração, que pode ser determinada pela natureza particular da locação como tal, a qual é sociologicamente estabelecida pelo tipo de relações de locação que mantém com outros membros da sociedade, diferentemente situados diante do processo histórico-social. (Foracchi, 1972, p. 20)

É bom lembrar que a reflexão de Foracchi sobre geração e juventude se enquadra no limite sociológico de uma juventude branca, urbana, de classe média e universitária, que protagonizou as rebeliōes estudantis no final da década de 1960. Deste modo, a autora busca a uniformização de uma determinada geração juvenil a partir do conflito determinado pela crítica a valores e perspectivas de adesão social de uma geração anterior pertencente a um mesmo grupo de locação. Eram universitários em crise com a preservação, transmissão e renovação de um patrimônio cultural, preocupados com suas possibilidades de atuação social e dinamização do sistema social mais amplo.

Ainda a propósito da noção de geração, Jean-François Sirinelli (1996) observa que é uma tarefa complexa responder o que é uma geração. O autor pergunta se a geração é um padrão que permite dividir o tempo ou se seria uma espécie de metrônomo que marca com regularidade o tempo que passa. Desse modo, por muito tempo, a tentativa de definir a noção de geração colocou o historiador diante do perigo da banalidade ou generalidade do propósito. Banalidade porque todas as sociedades humanas conhecidas estabelecem a sucessão de faixas etárias; generalidade porque, por esta mesma razão, "o uso da noção de geração fica às vezes na superfície das coisas, sendo antes elemento de descrição do que fator de análise" (Sirinelli, 1996, p. 132).

Sirinelli observa também que estabelecemos os limites de uma geração como elemento de "periodização" econômica, social, política e cultural. Só que se a noção de "periodização" remete à de regu- 
laridade, os fatos inauguradores de uma geração se sucedem de maneira forçosamente irregular e são de geometria variável em relação aos registros econômico, social, político e cultural. Isto promove gerações "curtas" e gerações "longas", plásticas em relação à verticalidade do tempo. Para este autor, a geração deve ser tomada então como uma escala móvel do tempo, como uma estrutura que contribui para reabilitar o acontecimento. Mais ainda, deve ser tomada como uma auto-representação, uma autoproclamação diferencial dos sujeitos diretamente envolvidos, assim como uma reconstrução do historiador que classifica e rotula.

Alba Zaluar (1997) afirma que, no Ocidente, o interesse científico pela juventude e sua definição como categoria analítica teve grande impulso nos anos 20, quando na cidade de Chicago, nos Estados Unidos, jovens italianos, judeus, irlandeses, afro-americanos, entre outros, formaram uma geração que se tornou objeto de estudos sistemáticos que discutiam as implicações entre juventude, violência, criminalidade e desorganização social urbana. Desde então, o trânsito zona rural versus zona urbana ou o esmaecimento de laços tradicionais de família e vizinhança foram vistos como favorecedores de atividades criminosas, violência e marginalização juvenil, suscitaram teorias que ora centradas na idéia de crise e desorganização soci$a l$, revelavam um compromisso com a ordem estabelecida e com uma forma homogênea de organização social; ora centradas na idéia de frustração, denunciavam o caráter competitivo de uma sociedade que não oferecia as mesmas oportunidades de ascensão para todos os grupos e categorias sociais; ora centradas no processo de rotulação de jovens moradores de guetos e bairros pobres como 'delinqüentes' pelo governo, pela polícia e pela justiça, observavam que, a rigor, se tratavam de jovens à deriva, vivendo conflitos próprios de idade (Zaluar, 1997).

Todas essas teorias foram, em maior ou menor grau, criticadas pelo seu compromisso com o positivismo que transformava as pessoas em objeto e seu comportamento em fatalidade ou determinação, dificultando o entendimento delas enquanto sujeitos que participariam de forma ativa nas suas escolhas e ações, apesar das constrições e pressões de forças de várias ordens (Jankowski, 1991; Katz, 1988; Matza, 1964). Por causa disso, nenhuma delas poderia explicar porque percentuais tão baixos de pobres, números pequenos de negros e poucas pessoas pertencentes a algumas minorias étnicas enveredam, de fato, em carreiras criminosas. (Zaluar, 1997, p. 20) 
No Brasil, a complexificação que a sociedade brasileira vem alcançando desde as primeiras décadas do século XX, através da emergência, organização e reivindicação política de novas categorias sociais urbanas como: operários, pobres, mulheres, negros, "desviantes" da lei ou da moral sexual, como prostitutas, homossexuais e jovens etc., em alguma medida deslocou o pensamento social do ponto de vista das elites. Assim, se os pesquisadores necessariamente não assumiram o ponto de vista destes novos sujeitos, defenderam ao menos a legitimidade da inflexão dos mesmos na sociedade (Durham, 1997). Desse modo, também a socioantropologia nacional sobre a juventude urbana, sob o impacto de teorias estrangeiras, de dinâmicas sociais internas e do surgimento de pesquisadores diretamente envolvidos com os seus objetos, vem refletindo sobre pequenos grupos de identidade juvenil circundantes e vem enfrentando a dificuldade ou a limitação de trabalhar com conceitos, categorias analíticas e ângulos de observação importados, muitas vezes inadequados para refletir sobre objetos, relaçôes e estruturas sociais geradores de dimensões simbólicas particulares.

\section{Juventude negra e música}

Ao propor refletir sobre a idéia de juventude através de sua relação com a música, necessariamente, não desprezo temas ou questōes como trabalho, educação, violência ou criminalidade. Observo, entretanto, que a despeito da importância de se pensar a relação entre juventude e estes temas citados, tal proposição acaba sempre repondo a idéia de juventude e a experiência juvenil no nível da falta de sentido em relação à sociedade civil organizada ou a estruturas sociais hegemônicas. Ao incidir, portanto, sobre a relação entre juventude e música negra, no âmbito da experiência de jovens negros na cidade de Salvador, considero este nível analítico comum, mas o reposiciono em direção a um excesso de sentido ou "excesso etnográfico"3 que esta experiência juvenil promove em relação à sociedade civil ou estruturas sociais hegemônicas. Considero o meio musical em Salvador uma estrutura social descritível, relacional, reflexiva e racializada, onde é possível identificar grupos juvenis de locação ou grupos geracionais móveis autoproclamados, auto-representados e exteriormente classificados como tal.

O binômio juventude negra e música tem despertado o interesse analítico de diversos autores no Brasil (Sansone \& Santos, 1997; Vianna, 1988; Vianna, 1997; Herschmann, 1997; Silva, 1995; Amorim, 1997; 
Félix, 2000; etc.). Na Bahia, os autores que escrevem sobre o assunto não institucionalizaram a discussão, mas dialogam entre si, influenciam uns aos outros, assim como absorvem também influências de estudos realizados em outras regiōes como o Rio de Janeiro (Sansone \& Santos, 1997). Logo, antes de tratar mais detidamente das minhas próprias notas etnográficas, vou me referir a alguns destes autores e estudos na Bahia. Antes ainda, considerando as constantes e importantes correspondências entre música e cultura negra que a Bahia e o Rio de Janeiro sempre estabeleceram, refletidas no meu trabalho e no de outros autores baianos ou radicados na Bahia, citados aqui, vou me referir a dois estudos realizados no Rio de Janeiro. Distanciando-me ou aproximando-me dos mesmos, pretendo então evidenciar vértices comuns que determinam culturas e identidades juvenis distintas.

Depois que galeras ${ }^{4}$ de funkeiros negros, pobres e favelados realizaram, em 1992, um fantástico "arrastão" nas praias cariocas, repercutido em todos os grandes meios de comunicação brasileiros, a pesquisa sobre o mundo funk carioca realizada pelo antropólogo Hermano Vianna (1988) tornou-se fonte de consulta para o governo do Rio de Janeiro e aparece citada em vários autores que posteriormente escreveram sobre o assunto. ${ }^{5}$ Desde então, a dimensão da festa, a relação entre o lúdico e a violência, é uma questão recorrente nos trabalhos sobre juventude e música funk no Rio de Janeiro.

Em $O$ mundo funk carioca (1988), Vianna lembra que seu interesse antropológico pelo funk e juventude funkeira surgiu casualmente quando, na condição de jovem da Zona Sul, simpático ao mundo do samba carioca, visitava a quadra da escola Estácio de Sá para ouvir samba e surpreendentemente se deparou com o "funk eletrônico na terra do samba”. Desde então, conheceu diversos bailes, fez amizades, definiu seu lugar de "espectador" atuante entre os funkeiros e "tradutor" do mundo funk carioca. Sobre o funk suburbano, Vianna defende que o mesmo é uma festa que se basta, que não serve para nada, não faz sentido fora de si mesmo. Não gera identidade étnica ou racial, não serve para formar novas amizades, valoriza a violência como mecanismo desencadeador de euforia e êxtase, não produz um funk brasileiro comercialmente dinâmico, não reatualiza a memória coletiva popular e negra das favelas e subúrbios cariocas, não faz crítica social.

Doze anos após a publicação desta pesquisa, o funk carioca é um fenômeno de mercado. Possui personagens como os DJ's, que produzem e comandam bailes, ou personagens como "o tigrão", "as 
cachorras", "as preparadas", “as poposudas”, sexualizados e definidores de uma ordem de relaçóes de gêneros em que o masculino parece ser sensual e virulento, o feminino parece ser sedutor e subordinado. Domesticado pela indústria da música, propaga um discurso de paz nos bailes, exotizado, atrai a simpatia da mídia, estimula a liberação sexual de jovens de "boa família", assim como contribui para a reificação da sexualidade e o uso do corpo, como sempre fizeram funkeiros pobres e negros. Ou seja, contra as conclusões de Vianna, o funk faz sentido dentro e fora de si mesmo, serve para alguma coisa. É possível constatar isso não só hoje, mas nas próprias notas etnográficas do autor. Por exemplo, Vianna definiu um papel e construiu amizades entre os funkeiros, manipulando sua identidade de "espectador atuante e tradutor do funk"; relata que rapazes e moças funkeiros dispunham de um tempo e espaço extra-bailes, quando ensaiavam complexas coreografias, formavam turmas e selecionavam vestuário e adereços para a festa, em que o excesso de cor era um aspecto marcante; observa também como nos bailes se executavam danças quase sempre em grupo e movimentos definidos como mais apropriados para homens ou mulheres; por fim, sugere um sentido ritualístico para brigas que, embora "acontecessem por acaso", sempre aconteciam, eram esperadas e mesmo estimuladas.

Vianna usa também o fato de que quase todo o tempo se dança e o fato de que quase não se conversa nos bailes para reforçar seu argumento de que o funk não serve para nada ou que não faz sentido fora de si mesmo. Descreve, entretanto, situações onde se estabeleciam relações de reciprocidade entre os dançarinos e os DJ's, quando, por exemplo, DJ's ocasionalmente "puxavam" um refrão e obtinham respostas que, mesmo quando pareciam "puro non sense", eram vinculadas a uma narrativa que todos conheciam. Relata algo mais sobre as danças que também o contradiz:

Outra dança que sempre aparece nos momentos de maior intensidade dos bailes lembra muito o samba de roda ou a dança de jongo. Os dançarinos se dão as mãos e formam uma roda, abrindo espaço para um membro do grupo solar no centro dessa roda. O solista escolhe quem vai substituí-lo no centro. Esse é o único momento do baile em que aparece o dançarino solo, mesmo assim rodeado por um grupo de amigos, que também controla o tempo de sua dança "solitária". Uma dança que também está se tornando popular nos bailes cariocas é o "esfrega-esfrega". Só as mulheres podem participar dessa dança: pernas entrelaçadas, seios colados, várias dançarinas amontoadas nas costas "esfregando" as nádegas, o 
ventre e muitas vezes simulando uma relação sexual. Essa dança só aumenta a carga erótica que perpassa todo o baile, do começo ao fim. (Vianna, 1988, p. 78)

Enfim, o erotismo das danças, a subdivisão dos dançarinos por gênero, o caráter performático do evento e a interdependência entre dança e música aparecem no funk, mas têm precedentes na memória de danças e músicas afro-descendentes no Brasil. Influenciada por Vianna (1988), Fátima Cecchetto (1997) observa e enfatiza a relação entre o aspecto lúdico e o violento nos bailes funk cariocas. Entretanto, diferente deste autor, ao apontar para diferenciaçôes de duração e distribuição espacial internas aos bailes, para hierarquias simbólicas criadas pelos próprios jovens funkeiros, identifica a formação de narrativas, identidades e laços que, apesar de fluidos e transitórios, justificam e ajudam a compreender o caráter violento dos funkeiros. Cecchetto (1997) apresenta o mundo funk do Rio de Janeiro como um universo de socialização de jovens pobres, suburbanos ou favelados, distantes do Rio de Janeiro urbanizado e sofisticado. Este mundo é marcado pela presença de rapazes cuja afirmação de identidade masculina é forjada através de um "ethos de virilidade". Deste modo, a violência no funk é uma atribuição exterior estigmatizante, mas é também um aspecto interno aos bailes, ritualístico, que aciona a produção de territórios e identidades através da constituição das galeras.

Com efeito, a adesão dos jovens às práticas das galeras do bairro ou do "pedaço" pode ser compreendida como uma afirmação da identidade grupal, que aparece associada à noção de "nós", em contraposição ao "eles", os jovens de outras galeras e de outras comunidades. É preciso ressaltar, entretanto, que essa rivalização entre nós e eles não recorta as relações entre as classes sociais; o que se estabelece são disputas intra-classe, entre os jovens de diferentes bairros populares, favelas e conjuntos habitacionais. (Cecchetto, 1997, p. 98)

Assim, onde para Vianna (op. cit.) não havia a possibilidade de formação de qualquer tipo de identidade e a festa só fazia sentido em si mesma, Cecchetto identifica "a representação simbólica de processos complexos que organizam a vida social das favelas, segundo uma lógica antagônica, territorial e guerreira" (idem, p. 114).

$\mathrm{Na}$ Bahia, a dimensão da festa, do lúdico e da violência reaparecem nos trabalhos de Suylan Midlej e Silva (1997) e Livio Sansone (1997). Silva, por exemplo, estudou o primeiro baile funk de Salva- 
dor, "Black Bahia", surgido em 1979, no bairro suburbano de Periperi. Segundo Silva, jovens entre 15 e 28 anos, moradores de bairros e regióes circunvizinhas, participavam todos os domingos à noite deste baile, dançando em grupos, sozinhos, circulando pelo salão ou observando a movimentação alheia. Apoiada no argumento de Vianna (op. cit.) de que a festa do funk não serve para nada e não faz sentido fora de si mesma e no argumento de Sansone (1993) de que a cultura negra juvenil aplaca o "stress racial", ${ }^{6}$ mas não é um reduto de fidelidade a sentimentos étnicos e raciais e sim o resultado da reinterpretação de símbolos negros norte-americanos globalizados, Silva segue a pista de que é o lúdico, reforçado pela ausência de violência sistemática no "Black Bahia", que define o perfil deste baile. Logo, estabelece como "objetivo central investigar o papel instituinte da comunicação mediática no processo de construção de identidade dos grupos sociais emergentes na contemporaneidade" (1997, p. 201). Defende, então, a presença de uma "etnicidade comportamental”, sem o teor político-ideológico característico do movimento negro instituído que nunca teria penetrado plenamente nos bailes.

Desse modo, Silva prefere enfatizar o "contágio de euforia", a "pulsão afetiva", o "estilo" como orientadores do sentimento de pertencimento entre os participantes do "Black Bahia":

Se é possível falar de uma "dimensão étnica" na construção da identidade do funqueiro de Periperi, essa dimensão não passa, em absoluto, pela consciência, pela interiorização de uma ideologia da negritude, pela ação planejada e organizada em torno de símbolos e projetos étnicos. Ela se configuraria, antes, pela imersão num padrão comportamental compartilhado, que se materializa, fundamentalmente, através do ambiente mediático contemporâneo. (Silva, 1997, p. 211)

As notas etnográficas da autora, entretanto, parecem nos revelar mais do que isso. Primeiro, há sim uma identidade ou "condição de classe" (Bourdieu, 1998) negada pelos informantes, mas evidente. Os freqüentadores do "Black Bahia” são basicamente jovens suburbanos, pobres e "negro-mestiços" com baixo grau de escolaridade e baixa capacidade de consumo. O baile tinha hora para começar - oito horas da noite - e não por acaso hora para terminar - em torno das onze horas da noite. Isto porque o sistema de transportes urbanos é extremamente precário em Salvador, sobretudo no subúrbio. Quem não volta para casa no último ônibus, 
com pouco ou nenhum dinheiro, dorme na rua ou volta à pé. As sofisticadas coreografias, os grupos de dançarinos são o resultado de horas de ensaio, quando se "curte" o funk em casa, na casa dos amigos, em outros bailes, festas ou eventos promovidos nos bairros. Silva classificou os jovens funkeiros como negro-mestiços, mas prefere não discutir porque estes mesmos jovens se classificam como "brancos, pretos, azuis, de toda cor" (1997, p. 213). Esta é uma questão importante, ao meu ver, uma vez que o "Black Bahia" ocorria em um contexto onde opera um continuum de cor que transforma cor em raça (Guimarães, 1999). Além disso, Silva esvazia a história social de manifestações culturais negras juvenis na Bahia. O caráter transnacional, a fluidez de identidades, a reatualização de símbolos africanos, a comunicação silenciosa e alternativa aos grandes meios de informação acontecem há um bom tempo na Bahia (Risério, 1981; Vianna, 1988; Cunha, 1991; Vieira Filho, 1997; Godi, 2001).

Livio Sansone (1997) levanta a questão de que versões locais de fenômenos globais como o funk relativizam o argumento de que haveria uma tendência homogeneizante e massificante de culturas juvenis a partir do centro anglo-saxão. Ou seja, teríamos contemporaneamente uma cultura juvenil globalizada, mas o consumo de música popular, a criação de identidade negra-juvenil no Brasil, ocorreria mantendose "uma série de aspectos tenazmente locais, determinados (por uma) história cultural, tradiçôes musicais e contextos estruturais diferentes. Em outras palavras, a hegemonia planetária da cultura juvenil 'anglosaxônica' não é incontestável” (Sansone, 1997, p. 221).

Desse modo, afirma Sansone, no Rio de Janeiro ou na Bahia, o funk é uma música comum, mas não caracteriza um subgrupo ou um estilo musical, concorre com vários outros estilos musicais. Pode servir para namorar, para agregar galeras ou turmas. Especificamente no Rio de Janeiro pode servir para manifestar oposição à ordem constituída e praticar violência. $\mathrm{Na}$ Bahia não existe ligação entre funk e narcotráfico ou prática sistemática da violência. Também na Bahia, o funk seria uma das formas de jovens pobres, "negro-mestiços", participarem da modernidade sem antagonizar a identidade factual e diferencial de baianidade. Nos dois contextos, entretanto, Sansone vê o consumo conspícuo como o meio para se alcançar a cidadania. Vê também uma ênfase na individualidade e a recusa a uma identidade negra diacrítica, nos moldes daquela elaborada pelo movimento negro. 
Ao escrever sobre juventude, reggae e samba-reggae na Bahia, Antonio J.V. dos Santos Godi (2001) discorda parcialmente de Sansone (1997). Para Godi, de fato, o reggae jamaicano e o samba-reggae baiano são reconstruçôes locais de representaçôes culturais juvenis originariamente anglo-saxãs. Entretanto, seguindo Paul Gilroy (1993), Godi observa que considerando o fato de que negros anglo-saxãos, jamaicanos e brasileiros compartilham o ônus de um mundo racialmente desigual e que a música se constitui como um agente estético que mantém um sentimento transnacional de pertencimento, não é exato afirmar que os países anglo-saxãos sejam o centro irradiador destas culturas juvenis. Num contexto global, a música é, para os negros, um símbolo afro-diaspórico que dispensa centro ou periferia, é um espaço de representação sem fronteiras. Logo, a despeito de aspectos etnomusicológicos locais, o reggae, o samba-reggae ou o funk poderiam ter se originado na Jamaica, no Brasil ou em terras anglo-saxãs. Em qualquer um dos casos, não por acaso, há sempre alguma referência ao símbolo África construído como locus mítico que promove um sentimento de origem, dispersão e reagregação simbólica, inclusive, no interior do mercado musical eletrônico.

Osmundo de Araujo Pinho (1998a) introduz um diferencial fundamental na reflexão sobre juventude negra e música ao enfatizar a questão do lugar como evento-território, onde são construídas identidades transitórias não essencialmente acopladas aos sujeitos, incorporadoras de historicidade, relações de força, informações globalizadas, constrangimentos raciais e de classe. No caso deste autor, a questão do lugar surgiu a propósito do estudo que fez no Centro Histórico de Salvador (Pelourinho), quando este Centro, depois de recuperado pelo Governo do Estado da Bahia, passou a abrigar diversos lugares onde jovens repartidos em termos de cor e classe ouviam música, dançavam e paqueravam. Em dois destes lugares, o "Bar Cultural" e o bar "Proibido Proibir", Pinho realizou uma etnografia comparativa.

Este autor afirma que o "Bar Cultural" era o cenário onde uma juventude universitária, branca, de classe média forjava uma identidade "alternativa" à cultura de massas popular de Salvador, ouvindo rock e $p o p$ e trocando "informaçôes culturais". Neste bar, o ingresso pago não determinava a qualidade específica da fronteira simbólica estabelecida, mas operava uma discriminação real. No "Proibido Proibir", grande parte das atividades se desenvolvia na rua. Muitos podiam passar, dar uma olhada, parar um pouco e seguir. O controle so- 
bre a territorialização era mínimo. A cultura espacial neste caso era permissiva e promíscua. A música tocada e dançada era o pagode.

Ainda segundo Pinho, uma personagem típica do "Bar Cultural" seria um rapaz branco, por volta dos 20 anos, de cabelos compridos nos ombros, roupas caras, brincos e tênis importado. Ia até o Pelourinho de carro. Era o "rei". Uma personagem típica do "Proibido Proibir" seria um rapaz negro, por volta dos 18 anos, de bermuda jeans com cintura baixíssima, de tênis Nike preto (provavelmente falsificado), cabelos rentes, bonés e correntes no pescoço, este rapaz era capaz de ter uma identidade real ou simulada com a violência e estava sempre pronto a sexualizar as relaçôes pessoais. Era o "brau". Por fim, diz Pinho que:

No caso das territorializações que apresentei, a música está sendo, por um lado, entendida como um sinalizador cultural, uma senha de identidade; por outro, como um elemento ativo que participa da elaboração do mapa cultural do Pelourinho. Essa música pode ser transnacional ou hiper-local. Ao mesmo tempo que é produto de toda uma série de fatores externos ao contexto de sua audição, ela é produtora de determinadas ambiências, tanto em um sentido concreto - pensemos nas boates que existem no Pelourinho - como no sentido de produzirem uma espécie de "trilha sonora" para uma comunidade interpretativa - pensemos no Bar Cultural, onde o rock é o índice de adesão aos valores partilhados. (Pinho, 1998, p. 44)

Quanto às minhas próprias notas etnográficas na cidade de Salvador, venho observando e refletindo sobre relações sociais associadas à dança e música negra. Primeiro estudei cultura juvenil e relaçôes raciais entre músicos da banda Timbalada, os timbaleiros (Lima, 1997). Atualmente, discuto cultura juvenil, raça e gênero através do estudo da experiência do samba (na forma pagode) na Bahia e observo pagodeiros (Lima, 2000). Em ambos os trabalhos, faço um recorte que inclui jovens dos 18 aos 25 anos de idade, mais ou menos escolarizados, bastante sexualizados e ansiosos consumidores; estes jovens não só consomem tanto quanto produzem música e danças. Através da música rearticulam um discurso sobre o mito da democracia racial, sobre a Bahia como reserva de autenticidade cultural no Brasil, mobilizam consciência racial atrelada à uma consciência corporal e conferem à música negra valor simbólico, mas também econômico (Dantas, 1994).

A dimensão racialista da música repõe, por um lado, para os jovens negros, a idéia da música percussiva como prática cultural "na- 
turalmente" negra. Na medida em que, nos últimos trinta anos, a música projetou uma imagem estereotipada, mas positivada da Bahia, legitimou comportamentos bastante estigmatizados no passado recente, se tornou um lazer da moda, um canal de mobilização social que dispensa a escola e o trabalho formal, atraiu muito mais os jovens e reforçou a idéia de que negros têm uma "veia natural para a música”. Entretanto, cresceu o número de músicos profissionais ou semiprofissionais na Bahia, poucos têm conseguido construir uma carreira sólida e menos ainda têm o controle da circulação do que produzem. Ou seja, os agentes das gravadoras, os maiores produtores de bandas e artistas, os donos dos grandes blocos carnavalescos não são estes músicos e não são jovens negros.

Por outro lado, muitos daqueles que ouvem, dançam e produzem esta música são amigos, parentes de outros músicos ou foram socializados em bairros periféricos onde muitas vezes há um terreiro de candomblé, um bloco carnavalesco, um grupo de samba onde se aprende a tocar e dançar. O terreiro, o bloco ou o grupo de samba, para além de seu caráter institucional, diversifica suas funçôes e significado, permitindo a jovens que pouco circulam pela cidade - por escolha, falta de dinheiro ou fidelidade ao território a que pertencem - o encontro, a acomodação de papéis de gênero, a construção de amizades, o aprender a tocar, a dançar, o compartilhamento de sentido para a música e as danças associadas e a elaboração de cultura juvenil.

Através de minha inserção etnográfica, distingo três grupos de locação e geracionais em que se elabora cultura juvenil: o primeiro pode ser representado pelo bloco afro-carnavalesco Ilê Aiyê, surgido em 1974, e está basicamente orientado pelo discurso da marca negra, ou seja, pela valorização da fenotipia mais negróide, pela idéia de África como ideologia e mito (Cunha, 1986). Este bloco forma músicos que tocam na banda Aiyê; o segundo pode ser representado pelo Grupo Cultural Olodum, surgido em 1979, e está basicamente orientado pelo discurso da origem negra, ou seja, pelo comprometimento político com a afirmação étnica e racial dos negros, o que significa relativizar a realidade fenotípica da negritude e propor uma redefinição da nação brasileira a partir deste lugar. Este bloco também forma músicos que tocam na banda do Olodum; o terceiro pode ser representado pela banda Timbalada, surgida em 1992, e está basicamente orientado pela conexão das noções de pessoa e indivíduo, ou seja, quando se mitifica a força de laços comunitários, a autoridade dos antigos transmissores de conhecimento, mas se evita a 
essencialização de identidades e a crítica racial apostando em respostas geradas por indivíduos emocionalmente autônomos e capazes de escolher de forma independente o seu destino num mercado musical globalizado, rentável para poucos e reificador da personalidade negra como plena de estímulos primitivos. Esta banda vem formando músicos que fazem muitos shows, viajam bastante, gravam discos e tocam no bloco carnavalesco, como o mesmo nome da banda, posterior ao surgimento da Timbalada.

Seguindo Sirinelli (1996), diria que estes grupos geracionais se auto-representaram e foram proclamados como tais pela mídia, por pesquisadores e um em relação ao outro; manipulam sentidos que não foram forjados no período que separa os dois limites da faixa etária que arbitrei acima; são objeto de, mas também têm forjado estruturas socioeconômicas. São formados por informantes que transitam de um grupo geracional a outro, às vezes, tocando de graça na banda Aiyê, do Ilê Aiyê, na banda do Olodum ou na Timbalada. Outras vezes como músicos remunerados, o que permite agregar à idéia de juventude negra não apenas valor simbólico (ser baiano, ser da banda do Ilê Aiyê, do Olodum, da Timbalada), mas material também (tênis importados, celulares, roupas coloridas e caras, colares, mulheres brancas). Para este tipo de trânsito, é fundamental ser um homem heterossexual e saber usar o próprio corpo como linguagem, mecanismo de assimilação, sedução do outro e, muito importante, como mercadoria.

Neste caso, acredito que pouco importa ou pouco interessa aos jovens negros elaborar e compartilhar uma idéia de juventude em relação ao que falta para a plena integração na sociedade civil organizada e em suas estruturas sociais hegemônicas. Ou seja, o trabalho, a escola, a recusa da violência e do crime são projetos alheios e só parcialmente assimilados. É mais eficaz, neste caso, elaborar e compartilhar uma idéia de juventude que ao invés de articulada em torno da falta de sentido, se articula em torno de sentidos nativos que aparecem como excessos etnográficos. Ou seja, é o corpo negro representado como tal na música que importa e muito interessa. É este corpo que, ao tocar e dançar, articula uma linguagem, põe e repõe estes jovens sujeitos em grupos de locação e geracionais relativos e reflexivos.

Em outras palavras, quero dizer que se a música para os negros em geral e para a juventude negra em particular, através de mimetismo, uso dialógico do corpo, reatualização de memória oral, 
promove conexões virtuais e alternativas com tradicionais territórios negros, com culturas negras várias, aponta para um pertencimento juvenil afro-diaspórico, remete também a um mundo juvenil negro perverso e racializado desde um longínquo estado. Funkeiros, timbaleiros e pagodeiros, enquanto jovens, são, no meio musical racializado, objeto de uma ideologia do erótico. Esta ideologia permite a busca no corpo do prazer sexual, a expansão da construção do desejo para além do que é visto como pecado e luxúria, a construção de uma cultura juvenil irreverente e sedutora. Entretanto, atrelada a estruturas de poder do gênero e da raça, legitima o corpo negro como mercadoria, torna-o um bem alternativo à ordem sexual para aqueles que podem pagar pela transgressão das proibições. $\mathrm{O}$ timbaleiro sensual, autoconsciente e assimilacionista, o pagodeiro "mal", "safado", "sexualmente potente", o funkeiro sensual e racialmente difuso, "num equilíbrio impossível", se tornam uma juventude que carrega a Bahia em suas cabeças (Moura, 1996), mas também em suas genitálias.

\section{Notas}

1. Guimarães (1999) se refere a "racialismo" ou racialização quando observa a crença de que determinados atributos morais, mentais, intelectuais, afetivos ou posições sociais são correspondidos a uma essência biológica racial. Na medida em que esta essência é sempre determinada pela cultura, é construída historicamente, atitudes, pensamento, idéias ou relações sociais racializadas se referem não a um sistema de causação, não a qualquer realidade biológica das raças, mas a ações subjetivamente intencionadas, hierarquizantes.

2. Sobre a idéia de "música", absorvo o ponto de vista de John Blacking (1992). Para este autor, "música" é tanto o produto de uma ação humana observável e intencional quanto um modo humano básico de pensamento através do qual uma ação humana pode ser constituída. A fonte mais acessível de informação sobre a natureza da "música”, diz Blacking, pode ser, primeiro, a variedade de sistemas musicais, estilos ou gêneros que são correntemente performados no mundo. Segundo, registros históricos, iconografia e descrição de performances. Terceiro, as diferentes percepções que as pessoas têm da música e da experiência musical, ou seja, os diferentes modos através dos quais as pessoas dão sentido aos símbolos musicais. Este sentido só pode existir compartilhadamente.

3. Michel De Certeau (1989) aponta o papel e o poder da escrita etnográfica em pôr os objetos e identidades em seu devido lugar, fazendo história daquilo que se esvanece num corte cultural de alteridade, na oralidade, na inconsciência, na espacialidade ou quadro sincrônico de sistemas sociais sem história. Neste caso, De Certeau opõe a escrita, "que invade o espaço e capitaliza o tempo", à palavra, "que não vai longe e que não retém". Dito de outra maneira, se "a escrita isola o significante da presença, a palavra é o corpo que significa, enunciado que não se separa do ato social de enunciação nem de uma presença que se dá, se gasta ou se perde na nominação" (De Certeau, 1989 , p. 217). Neste procedimento, a escrita produz um "resto", um excesso 
etnográfico ouvido, visto, mas não compreendido, que não se escreve, mas também define aquele etnografado.

4. Alba Zaluar (1997) observa que se começou a falar em galeras, em francês galères, na década de 1970, em cidades francesas e particularmente em Paris. Naquele contexto, o problema das galeras estava associado à questão nacional e étnica e em menor grau de classe. As galeras eram marcadas pela presença de jovens imigrantes árabes, caracterizados pelo sentimento comum de exclusão social, pela falta de organização interna, pelo descompromisso com o mundo do crime e falta de objetivos políticos claros. Se tratavam de jovens "à deriva", "niilistas" e "autodestrutivos. No Brasil, afirma ainda Zaluar, as galeras cariocas não evidenciam questóes nacionais ou étnicas, mas, como na França, são organizações sem chefia instituída, sem regras explicitadas ou rituais iniciáticos, descompromissadas com o mundo organizado do crime. Possuem uma estreita relação com os bairros de origem, com o espírito de festa e rivalidade dos bailes funk.

5. A propósito, em 1997, quando então trabalhava como pesquisador do Projeto S.A.M.BA (Sócio-Antropologia da Música na Bahia) da UfBA, organizamos um ciclo de seminários do qual participou o antropólogo Hermano Vianna. Naquela ocasião, o mesmo nos falou sobre o susto e incômodo que o tomou ao ser transformado pela mídia e governo cariocas em intérprete de um grande "arrastão", ocorrido no verão de 1992, quando então galeras de funkeiros saíram pelas praias cariocas "arrastando" pessoas e coisas, "agredindo", "assustando" e "roubando" banhistas. Em todo caso, as relações do autor com a mídia antecede o grande arrastão de 1992. O próprio autor conta na introdução do livro $O$ mundo funk carioca (1988) que foi o primeiro, depois do fenômeno Black Rio, em 1976, a escrever na imprensa carioca sobre as festas de jovens suburbanos agora embalados pelo hip hop. Já naquela ocasião, 1987, o autor confessa que seu artigo reavivou na imprensa carioca o caráter "exótico, selvagem e desconhecido", normalmente atribuído aos suburbanos.

6. A primeira vez que ouvi a expressão "stress racial", a mesma foi enunciada pela Profa Dra Maria Inês da Silva Barbosa, da UfMT, em 1999, no 20 Curso Avançado sobre Relações Raciais e Cultura Negra, promovido pelo Centro de Estudos Afro-Asiáticos. Como se tratou de uma enunciação oral, desde então, me reapropriei da expressão e a uso quando pretendo me referir a aspectos das relações raciais no Brasil que constrangem pela linguagem, pela troca de afetos, pelo contato sexualizado e assimétrico entre brancos e negros, a rejeição e crítica ao racismo brasileiro.

\section{Referências bibliográficas}

AMORIM, L.S. Cenas de uma revolta urbana: movimento hip hop na periferia de Brasília. 1997. 114f. Dissertação (Mestrado) Departamento de Antropologia, Universidade de Brasília, Brasília, DF.

BLACKING, J. Music, culture and experience. In: Byron, R. Music, culture and experience; selected papers of John Blacking. Chicago: University of Chicago, 1992. p. 223-242.

BOURDIEU, P. Condiçāo de classe e posição de classe. In: Bourdieu, P. $A$ economia das trocas simbólicas. São Paulo: Perspectiva, 1998. p. 3-25. 
CASTRO, N.A.; BARRETO, V.S. (Org.). Trabalho e desigualdades raciais: negros e brancos no mercado de trabalho em Salvador. São Paulo: Annablume, 1998.

CECCHETTO, F. As galeras funk cariocas: entre o lúdico e o violento. In: Vianna, H. (Org.). Galeras cariocas: territórios de conflitos e encontros culturais. Rio de Janeiro: UFRJ, 1997. p. 95-118.

CERTEAU, M. Etnografia: a oralidade ou o espaço do outro: Léry. In: Certeau, M. A escrita da história. Rio de Janeiro: Forense-Universitária, 1989. p. 211-242.

CUNHA, M.C. Etnicidade: da cultura residual mas irredutível. In: Cunha, M.C. Antropologia do Brasil. São Paulo: Brasiliense; EdusP, 1986. p. 97-108.

CUNHA, O.M.G. Coraçôes Rastafari: lazer, política e religião em Salvador. 1991. 334f. Dissertação (Mestrado) - Programa de pós-graduação em Antropologia Social, Universidade Federal do Rio de Janeiro, Rio de Janeiro.

DANTAS, M. Olodum: de bloco afro a holding cultural. Salvador: Grupo Cultural Olodum/Casa de Jorge Amado, 1994.

DURHAM, E.R. A pesquisa antropológica com populações urbanas: problemas e perspectivas. In: CARDOSO, Ruth (Org.). A aventura antropológica: teoria e pesquisa. São Paulo: Paz \& Terra, 1997. p. 17-37.

FÉLIX, J.B.J. Chic show e Zimbabwe e a construção da identidade nos bailes black paulistanos. 2000. 210f. Dissertação (Mestrado) - Faculdade de Filosofia, Letras e Ciências Humanas, Universidade de São Paulo, São Paulo.

FORACCHI, M.M. A juventude na sociedade brasileira. São Paulo: Pioneira; EDUSP, 1972.

GILROY, P. The black Atlantic: modernity and bouble consciousness. Cambridge, Mass.: Harvard University Press, 1993.

GODI, A.J.V.S. Reggae and samba-reggae in Bahia: a case of long-distance belonging. In: Perrone, C.A.; Dunn, C. (Ed.). Brazilian popular music and globalization. Gainesville: University Press of Florida, 2001. p. 207-219.

GUIMARÃES, A.S.A. Racismo e anti-racismo no Brasil. São Paulo: Editora 34, 1999. 
HERSCHMANN, M. (Org.). Abalando os anos 90 funk e hip-hop: globalização, violência e estilo cultural. Rio de Janeiro: Rocco, 1997.

LIMA, A. O fenômeno timbalada: cultura musical afro-pop e juventude baiana negro-mestiça. In: SAnsone, L.; Santos, J.T. (Org.). Ritmos em trânsito: sócio-antropologia da música baiana. São Paulo: Dynamis; Salvador: Programa A cor da Bahia e Projeto S.A.M.B.A, 1997. p. 161-180.

LIMA, A. O samba que não é carioca nem baiano. Interseçôes - Revista de Estudos Interdisciplinares, Rio de Janeiro, v.2, n. 1, p. 65-84, 2000.

MOURA, M. Produtora, mercadora, mercadoria: uma cidade para o carnaval? In: FISCHER, T. (Org.). O carnaval baiano: negócios e oportunidades. Brasília, DF: SEBRAE, 1996. p. 59-71.

PINHO, O.A. Alternativos e pagodeiros: notas etnográficas sobre territorialidade e relações raciais no Centro Histórico de Salvador. Estudos Afro-Asiáticos, Rio de Janeiro, n. 34, p. 35-48, dez. 1998.

PINHO, O.A A Bahia no fundamental: notas para uma interpretação do discurso ideológico da baianidade. Revista Brasileira de Ciências Sociais, São Paulo, v.13, n. 36, p. 109-120, 1998.

QUEIROZ, D.M. Desigualdades raciais no ensino superior: a cor na UFBA. In: QueIROZ, D.M. Educação, racismo e anti-racismo. Salvador: Novos Toques, 2000.

RISÉRIO, A. Carnaval Ijexá. Salvador: Corrupio, 1981.

SANSONE, L. Pai preto, filho negro: trabalho, cor e diferenças de geração. Estudos Afro-Asiáticos, Rio de Janeiro, n. 29, p. 65-84, 1993.

SANSONE, L. Funk baiano: uma versão local de um fenômeno global? In: Sansone, L. ; Santos, J.T. (Org.). Ritmos em trânsito: sócio-antropologia da música baiana. São Paulo: Dynamis; Salvador: Programa A cor da Bahia e Projeto S.A.M.B.A, 1997. p. 219-240.

SANSONE, L.; SANTOS, J.T. (Org.). Ritmos em trânsito: sócio-antropologia da música baiana. São Paulo: Dynamis; Salvador: Programa A cor da Bahia e Projeto S.A.M.B.A, 1997.

SILVA, C.B.R. Da terra das primaveras à ilha do amor: reggae, lazer e identidade cultural. São Luís: EDUFMA, 1995. 
SILVA, S.M. O lúdico e o étnico no funk do "Black Bahia". In: SANSONE, L.; Santos, J.T. (Org.). Ritmos em trânsito: sócio-antropologia da música baiana. São Paulo: Dynamis; Salvador: Programa cor da Bahia e Projeto S.A.M.B.A, 1997. p. 201-217.

SIRINELli, J.F. A geração. In: Ferreira, M.M.; Amado, J. (Org.). Usos $e$ abusos da história oral. Rio de Janeiro: FGV, 1996. p. 131-137.

VIANNA, H. O mundo funk carioca. Rio de Janeiro: Zahar, 1988.

VIANNA, H. (Org.). Galeras cariocas: territórios de conflitos e encontros culturais. Rio de Janeiro: UFRJ, 1997.

VIEIRA FILHO, R.R. Folguedos negros no carnaval de Salvador (18801930). In: Sansone, L.; Santos, J.T. (Org.). Ritmos em trânsito: sócioantropologia da música baiana. São Paulo: Dynamis; Salvador: Programa A cor da Bahia e Projeto S.A.M.B.A, 1997. p. 39-57.

ZALUAR, A. Gangues, galeras e quadrilhas: globalização, juventude e violência. In: Vianna, H. (Org.). Galeras cariocas: territórios de conflitos e encontros culturais. Rio de Janeiro: UFRJ, 1997. p. 17-58. 